\title{
LITERATURA Y CINE (DESDE ESTA LADERA: LA LITERATURA COMPARADA)
}

\author{
Luis Miguel Fernández
}

(Universidad de Santiago)

\section{EL OBJETO DE LA LITERATURA COMPARADA Y EL LUGAR DEL CINE}

A estas alturas del desarrollo de los diferentes campos de investigación de la ciencia literaria no resulta una novedad hablar de las relaciones entre el cine y la literatura. Basta con consultar cualquiera de los repertorios bibliográficos sobre el asunto para darse cuenta del creciente auge del mismo, aunque es justo reconocer que dicho crecimiento no es homogéneo, ya que al lado de países con una tradición muy consolidada como Francia o Estados Unidos, se encuentran otros que como España siguen sin prestarle la debida atención, fuera de las muy notables y válidas excepciones ${ }^{1}$. A pesar de ello, no siempre se han clarificado suficientemente ni el objeto de

1 Entre algunos de estos repertorios cabe citar a Ross (1987: passim), Paech (1988: passim), Gordillo (1988: passim) y Tenorio (1989, 1991: passim). Y entre las excepciones españolas que se han acercado al tema, aunque desde una óptica diferente a la que aquí se mantiene, es obligado destacar los varios trabajos de Utrera (especialmente, 1981: passim), Urrutia (1983: passim), Company (1986, 1987: passim) y Peña-Ardid (1992: passim). 
la investigación ni los planteamientos teórico-críticos adecuados para cada caso, ya que si bien están bastante claros los límites de determinadas disciplinas como la Semiótica y la Narratología comparadas, parecen estarlo un poco menos los de otras como la Historia de la Literatura o la Literatura Comparada.

Mi intención en el trabajo presente es la de acercarme a este último aspecto, con el deseo de contribuir al debate acerca de qué parcela de esa relación corresponde a la Literatura Comparada y, sin pretender agotar un tema que apenas ha sido tratado hasta el presente en nuestro país, la de reivindicar para ésta unas posibilidades de conocimiento semejantes o superiores a las de otras disciplinas más asentadas en este terreno.

Ahora bien, este camino no está exento de dificultades desde el momento en que los propios comparatistas de la literatura no admiten de buen grado al cine como uno de sus objetos de estudio; algo que se comprueba en el doble rasero con el que es tratado, porque si, por una parte, se lo excluye de las definiciones del objeto de la disciplina o se lo confina en territorios nebulosos como el de «influjo recíproco de las artes», por la otra, se asume que algún papel puede cumplir en el establecimiento del concepto de «literariedad» cuando se celebran congresos que tienen como tema el de las relaciones del cine con la literatura, como el de la Asociación Internacional de Literatura Comparada (Innsbruck, 1979), o el de la Sociedad Española de Literatura General y Comparada (Madrid, 1990).

Veamos, entonces, algunas de estas tomas de posición respecto al objeto de la Literatura Comparada y al papel del cine por parte de algunos comparatistas representativos.

Para René Wellek, que en 1963 afirmará que el problema esencial de la investigación literaria es el de la obra de arte literaria en sí misma (1968: 219), los paralelos entre las artes en general no contribuyen al progreso de nuestro conocimiento, siendo su estudio el objeto de una historia comparada de las artes y no de la Literatura Comparada (1969: 149-161).

Más confusos se muestran Claude Pichois y André M. Rousseau, quienes, aunque se refieren a las artes y nunca al cine, admiten que el significado de una obra o escuela literaria puede aclararse por el contexto artístico, y que la Literatura Comparada «es el arte metódico, mediante la indagación de lazos de analogía, de parentesco y de influencia, de acercar la literatura a los otros dominios de expresión o del conocimiento, o bien los hechos y los textos literarios entre sí...», pero en una segunda definición más restrictiva suprimen toda referencia a los «otros dominios de expresión». En cambio, son mucho más claros cuando afirman que los textos comparados han de pertenecer a varias lenguas o a varias culturas «con el designio de comprender mejor la Literatura como función específica del espíritu humano» (1969: 154 y 198-201). 
Coincidiendo con uno o con otros según los casos, Ulrich Weisstein dedica un capítulo de su importante libro a un «excurso» que titula «influencia recíproca de las artes» (1975: 297-316), en el que defiende que la ciencia de la literatura ha de ocuparse de las formas mixtas como la ópera, el oratorio, la cantata, las historietas gráficas y el cine, si bien un poco antes, y de forma contradictoria, incluye el estudio comparativo de la literatura y las demás artes en una historia y ciencia comparada de las artes, al igual que lo había hecho Wellek. Y queda claro también que un asunto es comparativo «cuando abarca dos literaturas o dos idiomas nacionales» (305).

Tampoco contribuyen a resolver el problema los alemanes Manfred Schmeling y Franz Schmitt-von Mühlenfels, ya que si para el primero todavía faltan claras reflexiones metodológicas (Schmeling, 1984: 5-38), el segundo pasa de admitir que la comparación de las obras artísticas es una rama legítima de la Literatura Comparada a difuminar los contornos de ésta en una más genérica ciencia general de la cultura; de ahí su escepticismo con respecto a la fecundidad del estudio recíproco de las artes, si bien un aspecto del mismo que le parece provechoso es el que afecta a las formas mixtas, entre ellas el cine, a las que incluye como objeto de la ciencia literaria. Al final es imposible saber cuál es el dominio de esa ciencia literaria, si el autónomo de la Literatura Comparada o el más general de la cultura (Schmeling, 1984: 169-193).

Álvaro Manuel Machado y Daniel Henri-Pageaux, ampliando los límites del comparatismo literario y aproximándolo a la Teoría Literaria, hacen del cine uno de sus objetos. Así, la Literatura Comparada se basa en relacionar «Duas ou mais literaturas, dois ou mais fenómenos culturais; ou, restreitamente, dois autores, dois textos, duas culturas de que dependen esses autores e esses textos», siendo lo más interesante de ese fenómeno cultural que es el cine el estudio de las adaptaciones cinematográficas de obras literarias (1988: 17 y 146).

En una postura metodológicamente más precisa y coherente, Adrián Marino trata de establecer una teoría literaria, apoyada en medios específicamente comparatistas que la liberen de las servidumbres que hasta el presente la Literatura Comparada ha tenido con respecto a la Historia de la Literatura y la Teoría Literaria. Para llegar a una poética comparada es preciso un nuevo paradigma, muy diferente en cuanto a su objeto de las meras relaciones de hechos con las que el comparatismo había venido trabajando tradicionalmente; paradigma que consiste en una teoría comparatista de la literatura con bases epistemológicas, metodológicas e históricas autónomas, que como toda poética trascendería los aspectos individuales de las obras hasta alcanzar unos "universales literarios», fundamento de la literatura universal y de la «literariedad», y fin último de cualquier búsqueda comparatista (1988: 144-145). 
Este objetivo requiere una hermenéutica comparatista que parta de presupuestos y métodos específicos; es decir, que recoja aquello más válido de la tradición comparatista y le dé una nueva orientación metodológica. De donde resulta un papel primordial para un concepto clave de esta tradición como es el de la invariante, el cual, al ocuparse de los elementos de estabilidad y permanencia de toda estructura literaria, sienta las bases de una teoría de la literatura y permite aprehenderla como «universalidad» 2 . Por ello, y atendiendo a que la literatura universal se compone únicamente de «todas las literaturas del mundo», parece clara la exclusión del estudio de las relaciones del cine con la literatura como objeto del comparatismo literario, ya que el estudio comparado de las artes no permitiría delimitar la especificidad literaria y no daría ningún resultado importante. Sería, pues, función de la Estética o de la Semiótica Comparada el ocuparse de dichas relaciones (245).

Menos radical y más equilibrado en sus planteamientos es Claudio Guillén cuando ante la pregunta de si es tarea del comparatismo literario la relación entre las artes y la literatura responde:

\begin{abstract}
En algunos casos pienso que sí, sin que haya por lo tanto cambio de jurisdicción, ni que ello suponga un espacio real o teórico distinto, equilibradamente interartistico. El centro de gravedad sigue siendo la literatura. Y entonces no hacen falta clases ni excursos suplementarios. Aludo a todo fundamento, o inspiración, u origen, pictórico o musical, de una obra de pura literatura. Aludo al estudio de fuentes, asiduamente practicado en este terreno, al de temas, y hasta al de formas (1985: 126).
\end{abstract}

Lo que significa que, aunque no siempre, en las ocasiones en las que lo literario es el objeto de la búsqueda comparatista se admite la conexión. En los otros casos, aquellos cuya finalidad es más bien teórica, los estudios interdisciplinarios deben caer del lado de la Estética, la Semiología, la Teoría de la Comunicación, etc. No se comprende muy bien, sin embargo, cómo en un razonamiento tan ponderado se limita el campo de las relaciones a la pintura y a la música, a no ser que, como establece más adelante, se piense en el cine únicamente en términos de forma mixta, objeto de otro tipo de investigaciones, y no como un arte semejante en cuanto a sus posibilidades interactivas a los otros dos mencionados. Por lo demás, y al igual que los otros comparatistas, establece como uno de los fundamentos de la Literatura Comparada el de la supranacionalidad [408] ${ }^{3}$.

${ }^{2}$ Su definición de la «invariante» es la siguiente: «un élément universel de la littérature et de la pensée littéraire", [...] un "caractère», un elément ou un trait "commun" du discours littéraire ou de la pensée littéraire (1988: 92).

${ }^{3}$ La tarea principal de la Literatura Comparada es la «investigación, explicación y ordenación de estructuras diacrónicas y supranacionales») (1985: 408). 
Por último, y aunque no desde el campo de esta disciplina, convendría señalar, por tratarse de autores españoles que escriben en un país en donde apenas se ha analizado este asunto con un mínimo rigor, los trabajos de Jorge Urrutia (1983: passim) y Carmen Peña-Ardid (1992: passim), en los que se defiende el estudio de la relación cine/literatura como objeto de la Literatura Comparada, si bien no siempre aparecen claramente precisados los límites de ésta con respecto a la Semiótica o la Narratología.

Detrás de esta casi generalizada exclusión del cine de la labor comparatista pueden verse dos ideas fundamentales: si el objeto de la disciplina es el de llegar a una literatura universal y a una poética comparada que alcance a definir la literariedad a través de la comparación de estructuras supranacionales, no parece que la relación cine/literatura tenga que ver con ese específico literario; pero, además, la defensa de la autonomía y la supervivencia de la Literatura Comparada depende de la no confusión con espacios teóricos que no le son propios y en los cuales cabría situar mejor dicha relación.

Ahora bien, si la segunda puede ser justificable en alguno de sus extremos más difícil parece serlo la primera. Y ello es debido a que desde la hermenéutica de Gadamer (Warning, 1989: 81-88), que estableció que la historia de la comprensión de una obra es siempre una historia de los «efectos» que la misma causa en los sucesivos intérpretes, y desde la de Hans R. Jauss (1976: 131-211, 1978: 81-122), al afirmar que la obra surge de la superposición de los diversos planos temporales, espaciales y culturales desde los que las diferentes lecturas del texto se le van incorporando, sabemos que el sentido y la forma de las obras no son unas constantes objetivas que permanezcan al margen de su percepción a lo largo de la historia, sino que van variando de modo progresivo a través de los cambios en el horizonte de expectativas de sus lectores, creando así una distancia hermenéutica que convierte a la obra en un producto de la interacción entre el texto y su público. Pero, al margen de esta dimensión histórico-sociológica de la lectura, el texto puede llevar codificada dentro de sí una instancia productora de sentido que es lo que W. Iser denomina el lector implícito, en la que convergen el potencial significado del texto y su actualización por el lector mediante el acto de lectura $(1975,1987)^{4}$.

El comparatista ha de preguntarse, entonces, acerca de la recepción de autores, obras, géneros, estilos, etc., de una literatura en otra, o acerca de la analogía que por un proceso de poligénesis o no puede darse entre ambos, y al hacerlo así no puede prescindir de la proyección que sobre las mismas hagan sus lectores, sea para confirmar sus expectativas de lectura o para variarlas, creando una distancia estética objetivable entre el objeto literario

${ }^{4}$ He aqui lo que dice Iser acerca del «lector implícito»: «This term incorporates both the prestructuring of the potential meaning by the text, and the reader's actualization of this potential through the reading process» (1975: XII). 
y su lectura. De donde se desprende que cualquier intento de poética comparada ha de contar inexorablemente si quiere tener algún tipo de virtualidad heurística, con ese círculo hermenéutico intersubjetivo que forman autor y lector, siendo por tanto metodológica y epistemológicamente posible no sólo el concebir textos literarios que lleven codificadas posibilidades de lectura cinematográficas, sino también que su recepción en una literatura dada desde otras de su entorno cultural no sea separable de la idea que de un determinado cine puedan tener sus autores y lectores. $Y$ es evidente que cualquier propuesta de invariantes o de literatura universal pasa por las semejanzas que las diferentes lecturas hayan ido aportando a las obras, aunque sean de origen cinematográfico.

Así, por ejemplo, no sería posible el estudiar las analogías o recepción de las vanguardias y el surrealismo franceses en la España del primer tercio del siglo veinte prescindiendo de la visión que en ambos se tiene del cine como ruptura del universo literario anterior, o de la concepción del cine como disolución de la racionalidad y la mezcla de sueño y realidad que no había en la literatura de la época; es decir, que el cine contribuye a establecer un nuevo horizonte de expectativas en los autores franceses y españoles, y su presencia se percibe en los textos ${ }^{5}$. Y de igual modo, si se tratase del modernismo de las primeras décadas del siglo habría que tener en cuenta las interferencias del cine en la novela de algunos de estos autores (G. Stein, J. Romains, M. Proust, V. Woolf y J. Joyce), tal como han sido señaladas por Keith Cohen (1979: passim)). Ni, finalmente, tampoco resulta fácil comparar los neorrealismos literarios español e italiano del período de posguerra sorteando el papel del cine, de cuyas interrelaciones surgen en muchos casos temas y procedimientos, como después veremos.

Pero, además, este cambio de expectativas con respecto a los géneros existentes que el cine introduce es perceptible en las opiniones de los autores, como en Robbe-Grillet:

\begin{abstract}
En la película, las cosas sólo existen como fenómenos; tienen obligatoriamente una forma, y ésta es presentada de un lado o de otro, pero nunca de varios lados al mismo tiempo; en cuanto a su interior, no tiene realidad más que cuando logra mostrarse al exterior. Influida o no por tales exigencias del relato cinematográfico, la novela a su vez parece tomar conciencia de esos mismos problemas. ¿Desde dónde se ve este objeto? ¿Bajo qué ángulo? ¿Con qué claridad? ¿Se detiene en él la mirada largo tiempo? ¿O pasa sobre él sin fijarse? ¿Se desplaza el objeto, o está fijo? El novelista, perpetuamente omnisciente y omnipresente, se ve así rechazado (Mitry, 1989: 449-450) ${ }^{6}$;
\end{abstract}

5 Para los autores franceses, A. y O. Virmaux (1976: passim), Clerc (1981: 303-307) y Hedges (1983: passim). Para los españoles, además de algunas referencias en Urrutia (1983), véase Morris (1972, 1980: passim). Para algunos aspectos resulta interesante VVAA (1991: passim).

6 En otro lugar afirma que lo que atrae del cine a los novelistas son sus posibilidades en el terreno de lo imaginario (1973: 166-167). 
y en los españoles Pere Gimferrer y Francisco Ayala, quienes han señalado una penetración muy profunda del cine en la literatura, hasta el punto de llegar a modificarla y condicionarla notablemente:

el cine ha contaminado, influido e incluso modificado profundamente en algunos aspectos o casos concretos la estructura de la narración literaria [...]; pero apenas puede dudarse tampoco de que muchos recursos hoy usuales en la narrativa desde Robbe-Grillet hasta la actual vanguardia hispánica - no se explican sin el precedente del cine (Gimferrer, 1985: 86-87).

Y por lo que se refiere al cine -este arte fundamentalmente del presente histórico-, es evidente que no se limita a nutrir la imaginación e inspirar las actitudes, costumbres, gestos y ademanes de la gente; también alimenta a esa otra arte de la que a su vez él mismo suele nutrirse: la literatura; tanto, que apenas habrá hoy obra de ficción narrativa o poética de cuyo contenido pueda decirse que está ausente la experiencia cinematográfica (Ayala, 1991: 16).

He aquí por tanto, una serie de opiniones de autores que, hablando desde la experiencia de la creación o desde su experiencia de lectores, confirman la presencia del cine en la literatura como algo innovador con respecto al paradigma literario existente.

Vemos, pues, un campo de las relaciones literatura/cine que puede y debe ser abordado por la Literatura Comparada: el de la presencia del cine en la literatura siempre que la misma redunde en un conocimiento de lo literario, y ello desde una perspectiva supranacional que tienda hacia una poética comparada y una literatura universal. Más dudosos me parecen, en cambio, los casos de las adaptaciones cinematográficas de textos literarios y de las fórmulas mixtas del tipo "ciné-roman» y «roman-scénario», ya que en ellos el objeto principal no es el estudio de la especificidad literaria, sino el de una forma de transcodificación de un medio a otro y el de los códigos de un género nuevo, el de los diversos modos de enunciación que puedan conducir a un conocimiento de los procedimientos narrativos del relato en general - y no sólo los del relato literario-, y el del posprocesamiento o recepción de un texto literario en una determinada época y cultura; por lo que habría que adscribir a ambos más bien a la Semiótica y Narratología comparadas ${ }^{7}$ y también, en el caso de las adaptaciones, a la Historia de la Literatura de cada país cuando se trate de saber la acogida de un texto en un período determinado. De igual modo, a esta última parecen corresponderle las aproximaciones de los escritores al cine en las diferentes épocas

${ }^{7}$ Kibédi Varga sostiene que la relación artes/literatura es un objeto de la Semiótica Comparada (1981: 216), mientras que Bruce Morrissette habla de especialistas en «estructuras comparadas» (1985: 69). Por su parte, para Jorge Urrutia el de las adaptaciones no es un problema de Literatura Comparada sino semiótico (1992: 30). 
históricas y el caso de los llamados talentos dobles, es decir, el de los escritores que son a su vez cineastas.

Cabe, entonces, plantearse hasta qué punto la Literatura Comparada puede servirse de otras disciplinas teóricas para el estudio de estas conexiones, sin abandonar por el camino su autonomía en beneficio de un mal entendido sincretismo teórico, y cuál es su terreno propio $-\mathrm{y}$, por qué no, su ventaja- con respecto a aquéllas.

\section{DE LA NARRATOLOGÍA A LA POÉTICA COMPARADA}

La francesa Marie-Claire Ropars-Wuilleumier afirma que «le texte moderne ne laisse jouer de la vue que dans la menace de la cecité», no permitiendo conocer de la imagen más que la espera y la ausencia (1990: 11), y ello para mostrar el asedio del cine al espacio tradicionalmente reservado a la novela: el perspectivismo. Limitación del campo de la novela que Italo Calvino había traducido bastantes años antes citando el ejemplo de un célebre caballo, porque "por donde pasa el cine ya no puede crecer ni una brizna de hierba» (1983: 92). Pero esa ausencia de visión que la investigadora francesa atribuye a las novelas de Céline, Malraux, Camus, Sartre o Robbe-Grillet, ha llevado, paradójicamente, a iluminar unos modos de escritura en los autores que difícilmente podrían entenderse sin el paso del cine por la literatura. Piénsese, por ejemplo, cómo en el caso del último autor citado esa "ceguera» que caracteriza a sus observadores, que siempre arrastran un déficit de visión, sirve para mostrar, en palabras de Bruce Morrissette, que «the bases of film novel analogies are constantly shifting» (1985: 20): cuando en La Jalousie se nos representa a la mujer del celoso marido y a su amante en una habitación de hotel haciendo el amor tal como es imaginado por aquél, y más tarde se observa la explosión del auto del amante, ambas escenas, que están separadas en la novela, aparecen, sin embargo, unidas por el término «accélère» aplicado tanto al frenesí erótico de la primera escena como a la aceleración del coche en la segunda. Transición literaria equivalente al fundido cinematográfico que demuestra cómo el cine ilumina un episodio de la novela $(1985: 19,32)$.

Este ejemplo nos introduce, por otra parte, en las posibilidades que el análisis narratológico ofrece para una adecuada comprensión de los intercambios que fluyen del cine a la literatura; y es que más allá de los casos evidentes en los que un procedimiento cinematográfico es citado en un texto literario o aparecen los que Umberto Eco llama cuadros intertextuales (aquellas situaciones típicas del cine que el lector reconoce desde su enciclopedia como pertenecientes al discurso cinematográfico) (1981: 116-120), es posible aplicar dicho método a otros textos en los que faltan referencias 
tan explícitas como un punto de partida válido para la Literatura Comparada, si bien ésta puede sobrepasarlo y orientarse hacia direcciones a las que la Narratología no llega por la propia limitación de su objeto. Por eso, el problema de las relaciones puede ser abordado apuntando hacia lo literario, siempre que como dice Morrissette, se solucione satisfactoriamente la cuestión de las equivalencias estilísticas entre las dos artes (1985: 58).

Permítaseme, pues, empezar con un fragmento de Aldecoa perteneciente al comienzo de su cuento "Vísperas del silencio»:

\begin{abstract}
Al asomar la cabeza quedó deslumbrado. Miró hacia abajo, hacia la penumbra de donde él surgía. Entre sus botas de goma, negras, brillantes, vio el rostro de su compañero mal afeitado, prematuramente viejo. Cerró los ojos un instante. Respiró. Todavía el olor pegajoso, dulzón, nauseabundo, aunque ya menos fuerte. Luego recorrió con la mirada su propio cuerpo: el pantalón de pana amarilla con las botas hasta media pierna; la bragueta casi sin botones con el cinturón bajo el ombligo; la camisa caqui haciendo una arruga, una bolsa por cima del cinturón; el jersey azul corto, demasiado corto y fino de tanto lavado; el chaquetón abierto, grande, caído, como las alas de un pájaro muerto...
\end{abstract}

Alzó la cabeza. El asfalto mojado reflejaba la luz de un sol de mediodía enfundado entre nubes. Sintió en la nuca unas punzadas al ruido de las llantas de un carro que pasaba tras de él. El final de la calle se difuminaba en un halo de niebla clara. Respiró con libertad, profundamente, hasta sentir dolor dentro de la nariz, en la cabeza, como cuando se lavaba y el agua le penetraba por las fosas nasales. Luego estornudó. Desde la acera un chiquillo le miraba curioso y espantado a un mismo tiempo. La voz del compañero de abajo le ascendió sorda, apremiante:

_Sal ya (1981: 55-56).

Ninguna marca explícita caracteriza el texto como cinematográfico. Aparentemente al menos, se trata de un narrador omnisciente de tipo tradicional que comienza su discurso in media res, de forma bastante habitual en el neorrealismo literario español, con el fin de ilustrar un trozo de vida de la existencia de unos poceros del ayuntamiento, los cuales trabajan en la limpieza del alcantarillado, bajo el suelo de la ciudad. La descripción de las ropas del personaje se mueve también hasta cierto punto dentro de lo habitual en las descripciones de la novela decimonónica, tal como ha sido estudiada por Philippe Hamon: hay unas demarcaciones inicial («recorrió con la mirada su propio cuerpo») y final («Alzó la cabeza»), se señala el tema de la misma (el cuerpo), y se sigue una distribución interna de los elementos que la componen y que evitan la enumeración indefinida al establecer un procedimiento de clausura (de abajo arriba, con la impresión desoladora del final que da un sentido ideológico a todo el conjunto: «como las alas de un pájaro muerto...») (1981: 180-197).

No obstante, y a pesar de todo lo anterior, hay algunos rasgos que llaman la atención. En primer lugar, la falta de una justificación temática 
de la descripción, ya que siempre que en la novela decimonónica un personaje ve algo y ello es descrito por el narrador ese ver reclama una justificación: el personaje que a lo largo de su camino se encuentra con un paisaje determinado que le llama la atención, aquel otro que se asoma a una ventana para entretener una espera y mientras tanto contempla lo que se ve desde la misma, etc. Es decir, que se trata de un sintagma narrativo estereotipado (un querer ver / un saber ver / un poder ver / el ver / la descripción) cuya única función es la de introducir lo descriptivo (Hamon, 1981: 185-187). Aquí la descripción no es coherente con los intereses del personaje: de él se nos manifiesta una preocupación por el olor y la limpieza («Todavía el olor pegajoso, dulzón, nauseabundo, aunque ya menos fuerte, Respiró en libertad [...] como cuando se lavaba y el agua le penetraba por las fosas nasales»), pero al mirarse sus ropas aparece otra preocupación distinta, la de una determinada situación vital, la de la pobreza y el desastimiento (un jersey gastado por tanto lavado y un chaquetón "caído como las alas de un pájaro muerto...»). Además, no tiene ningún sentido el hecho de mirar unas ropas que ya conoce de sobra, sólo estaría justificado para buscar algo especial en ellas, pero el texto no indica esa búsqueda.

En segundo lugar que, frente a lo característico de la pausa descriptiva en la narración literaria decimonónica, que es el no consumir tiempo narrativo e imponer una ralentización de la diégesis (Genette, 1972: 128-129, 133-138) ${ }^{8}$, Aldecoa integra la descripción como parte fundamental del tiempo diegético: el que el personaje se contemple retarda la acción de salir y justifica el apremio de su compañero («Sal ya»), y además convierte en parte de esa diégesis, de la acción narrativa, la voz del narrador, que con su saber y sus comparaciones se había situado en una dimensión extradiegética.

La clave de ambos hechos parece estar en el recorrido visual de su cuerpo que hace el pocero, al permitir una descripción necesaria para el narrador y la no interrupción de la narración al mismo tiempo. El narrador, que ha iniciado bruscamente su discurso, va intercalando los datos de un mundo que existe previamente y que se encuentra en la obligación de ir enunciando desde su omnisciencia, por ello el pasaje descriptivo le corresponde a él y no al personaje, cuyos intereses son otros, pero como muestra a unos personajes moviéndose dentro de ese mundo, actuando en él, no puede frenar mediante la pausa descriptiva, el dinamismo de la acción, en la que se inserta su propia voz; de ahí que sitúe el lugar de la mirada en los ojos del personaje. Nos encontramos así con un centro focalizador, el del narrador que sabe, tiene la palabra y describe, y una mirada, la del personaje, que también contempla su propio cuerpo pero progresivamente es sustituida por la del narrador (cuando éste aporta una serie de datos

${ }^{8}$ Genette atribuye a la descripción de Proust un carácter innovador en cuanto a que en él se integra en el proceso narrativo. 
situacionales). $\mathrm{O}$, dicho con las palabras de François Jost, estamos ante un caso de discrepancia entre una focalización (la del narrador) y una ocularización interna (la del personaje) (Jost, 1983, 1989: passim).

Ahora bien, esa discrepancia tiene mucho de cinematográfica. Pensemos, por ejemplo, en que lo que caracteriza a la descripción filmica es que no existe fuera del flujo narrativo, carece de la autonomía que tiene en la narración literaria al estar sometida al «imperialismo de la acción» (Vanoye, 1989: 106). Tan sólo el principio de algún filme, antes de que se introduzca a los personajes, podría considerarse descriptivo, pero ello es debido no a una detención de la historia sino a que ésta todavía no ha comenzado (Chatman, 1980: 129). Por ello, aunque todo plano puede contener elementos descriptivos, ningún plano es enteramente descriptivo, porque, como afirma Brian Henderson «Even if action no occurs in this shot or in this setting, the time devoted to them builds espectations for action to come; they too are ticks on the dramatic clock» (1983: 10). Y de ahí deriva esa otra diferencia con la descripción literaria, la inmediatez visual de la imagen, que no permite fragmentar el objeto descrito en sus diversos componentes (forma, color, situación, etc.) ni admite el carácter predicativo de la frase (el ojo del espectador no ve necesariamente los atributos del objeto como sí está obligado a hacerlo en el texto literario) (Ricardou, 1967: 6979; Vanoye, 1989: 93); o, lo que es igual, la falta de redundancia frente a la narración literaria que sí la exige (la novela necesita la visualización de un objeto verbal mediante un comentario también verbal, el cine no, debido a su inmediatez), base de la diferente narratividad que Robert Scholes atribuye al cine y a la novela (1982: 67).

En el texto de Aldecoa la expansión descriptiva de la serie de prendas lleva en la parte final una serie de determinaciones adjetivales que no tienen nada que ver con el cine, pero sí resulta muy próximo a éste la dinamización, el movimiento de la pausa descriptiva, que se integra en la diégesis por medio de una doble vinculación: el recorrido de la mirada contribuye a provocar la impaciencia de su compañero y a señalar la fractura que se produce entre la imagen y la voz, ya que al lector se lo sitúa en la mirada del personaje mientras que la voz narradora desmiente que lo que se dice del cuerpo le pertenezca a otro que no sea el propio narrador. Pero, además, se observa la presencia de un mecanismo propio de la imagen y que funciona para el lector como un intertexto de origen filmico: el movimiento de la mirada es semejante al que se produce a través de la panorámica vertical - uno de los dos medios descriptivos por antonomasia junto al travelling-; algo que se confirmará posteriormente mediante otra descripción muy semejante pero en la que el referente fílmico está explicitado:

Mercedes despegó la vista de su labor al sentir acercarse a su marido. Sus ojos vieron un primer plano de pies nonagenarios llevándose la cera de la tarima. Alzó 
la vista y recorrió por entero el cuerpo de Crisanto. Pantalones de pana negra arrugados, jersey deportivo, camisa blanca, abierta. En el rostro, un gesto interrogante (1981: 63).

El detallismo que acabamos de ver en Aldecoa tiene una de las plasmaciones más escoradas hacia lo cinematográfico de todo el período de posguerra en la prosa de Fernández Santos, autor que no sólo se dedicó profesionalmente a la realización filmica sino que dejó bastantes manifestaciones acerca de su interés por el cine. En una de sus novelas menos conocidas, En la hoguera, se lee lo siguiente:

La muchacha fue siguiendo el curso del río y cruzó por las piedras, en tanto el cielo se cubría de haces resplandecientes. Un poco antes de llegar a la ermita vio al gitano, como siempre en cuclillas, escarbando la corriente con una varita. El paraje solitario asustó a Soledad, pero, cuando pensó en volver atrás, ya el gitano le hablaba.

- ¿Dónde vas?

-De paseo

-Oye, ven...

¿QQué quiere?

-Verte...

Ya estaba como siempre. Cada vez que la encontraba repetía las mismas palabras, hacía las mismas cosas. Ahora estaba acariciando su brazo con el junco mojado.

- ¿No se puede estar quieto? — protestó.

El hombre no contestó, sólo la miraba.

\section{XXII}

El pie desnudo, clavado en el lodo, surgía entre los juncos, y, en torno a él, alrededor del muslo, rasgado de violáceos arañazos, una nube de mosquitos zumbaba vorazmente, posándose en la sangre. El curso del agua bañaba los desgarrones del vestido, dejando un sedimento de espuma amarilla, de infinitos corpúsculos brillantes. Al ver los juncos moverse y su pie hundirse aún más en el lodo, Inés ante aquella carne magullada, maltrecha, se sintió desvanecer (1976: 243-244).

Este fragmento reproduce el final del capítulo XXI y el inicio del siguiente, y narra la violación de Soledad por el gitano Alejandro y el encuentro de su cuerpo por su amiga Inés. El narrador apenas manifiesta su omnisciencia, en contraste con otros muchos pasajes de la novela, y se limita a servir de soporte o puente a las miradas de ambos personajes en los dos capítulos. Así, después de la mirada del gitano se producen una violenta elipsis y una especie de fundido encadenado que aparecen significados en el texto de dos maneras: por el efecto de la mirada cercana de 
Alejandro que se prolonga en el recorrido visual de Inés sobre el cuerpo de la herida Soledad, y mediante una serie de términos e isotopías que se repiten y tienen funciones equivalentes (la caricia con el junco sobre el brazo desnudo de Soledad se corresponde con los juncos que resaltan la desnudez del pie en medio del lodo; es decir, los juncos destacan en los dos casos la desnudez e indefensión de la muchacha).

Al mismo tiempo, y para que el lector no pueda pensar en ningún momento que la visión corresponde al narrador, éste utiliza varias marcas que muestran su ausencia: sitúa el cuerpo oculto por unos juncos, de modo que su descripción detallista esté justificada para una mirada que haya de vencer tal dificultad y no para un narrador omnisciente que no necesitaría recurrir a tal procedimiento; aumenta la cercanía del objeto con la intención de reproducir tanto la proximidad física de Alejandro, causante de la desgracia, como la proximidad física y afectiva de Inés; y reitera la visión sobre los juncos y el lodo («El pie desnudo, clavado en el lodo, surgía entre los juncos», "Al ver los juncos moverse y su pie hundirse aún más en el lodo...») para señalar el cambio de una mirada asombrada a otra conocedora de la personalidad de la muchacha; es decir, de una mirada de conocimiento a otra de reconocimiento. Y al hacer protagonista de la descripción a la mirada de Inés en ocularización interna, introduce lo descriptivo dentro de la temporalidad interior del personaje observador y lo aleja de cualquier posible separación del tiempo narrativo: es la ansiedad de Inés quien le hace ver el cuerpo de Soledad de ese modo, con lo que dicha visión puede responder tanto a un hecho objetivo, externo al personaje, como a un contenido mental de quien lo contempla desde la proximidad fisica y afectiva.

La indecisión entre atribuirle la realidad del cuerpo de Soledad a un narrador $u$ otorgarle el carácter de contenido de la mente de Inés, es pareja a la que se produce en el estilo indirecto libre, en el que no siempre es posible decidir con exactitud si corresponde al narrador o al personaje, pero parece más cinematográfica que éste en la medida en que no suele encontrarse en la novela con las características que aquí presenta y sí, en cambio, es habitual en el cine, en el que cuando se trata del uso de la cámara subjetiva a veces resulta dificil saber si lo que la cámara encuadra existe fuera de la mente del personaje o no. En cualquier caso, en el ejemplo de Fernández Santos creo que se podría hablar de una gran semejanza con lo que Marc Vernet llama "campo personalizado» o también el en "deça» de la cámara, una de las «figuras de la ausencia», que consiste en la recepción por un campo ordinariamente neutro de una serie de marcas particulares que remiten a un personaje cuya posición geográfica o psíquica asume en parte o en su totalidad la cámara (por ejemplo, cuando en Yakuza, de S. Pollack, un travelling hacia delante muestra al personaje de espaldas, el temblor de la cámara indica la impaciencia de ese personaje que, sin embargo, aparece dentro del campo visual; o cuando en La noche de Halloween, de J. Carpenter, las aproximaciones y alejamientos de la cámara 
muestran la presencia amenazadora del asesino) (1988: 29-58). También en el texto de En la hoguera se perciben esas marcas equivalentes a las visuales, como ya quedó dicho, que revelan la presencia de una figura ausente, la ansiedad de Inés que se proyecta sobre el cuerpo de Soledad.

Vemos, pues, a través de estos ejemplos como un texto literario puede llevar codificadas en su interior una serie de inscripciones narrativas y estilísticas que lo aproximan al cine. Sin embargo, y según lo que antes se dijo, la obra no existe en cuanto tal hasta que no es actualizada mediante el proceso de lectura, con lo que cabe hablar de unos objetos literarios que sólo pueden darse en la conciencia lectora de un modo esquemático y que, como se desprende de la fenomenología de Roman Ingarden, al que sigue $\mathrm{W}$. Iser, son objetos que al carecer de correspondencia con el mundo exterior presentan un carácter múltiple, llenos de lagunas en su descripción que provocan esos puntos de indeterminación - o vacíos según Iser- que la conciencia receptora debe llenar mediante su concretización en el acto de lectura (1979: passim) ${ }^{9}$. Uno de estos puntos de indeterminación se crea cuando el texto no se completa según el paradigma literario que le sirve de punto de partida, sino que recurre a otro tipo de codificaciones como la cinematográfica. Se origina, entonces, una escisión que provoca la extrañeza del lector, ya que a éste se le anticipa algo que después no se cumple y se le obliga a resituarse dentro del texto de un modo diferente, variando sus ilusiones de lectura ${ }^{10}$.

En los textos neorrealistas citados observamos esa "extrañeza» prevista por el propio texto en la medida en que dentro de un paradigma más o menos tradicional y decimonónico de narración, aparece una apertura hacia otras posibilidades que lo cuestionan, obligando al lector a fijar un itinerario de lectura que se sirve de la anticipación y la retrospección sobre lo leído - en los textos de Aldecoa se anticipa primero un modo narrativo, el tradicional, que inmediatamente resulta cuestionado por la introducción de elementos ajenos al mismo de origen filmico, y más tarde el segundo fragmento confirma esta interpretación pero resitúa al primero no como hecho aislado sino como parte de una estrategia del texto, que tiende a explicitar una mirada que no es la del narrador sino la de los personajes-, y en el que es posible no sólo el descubrir las referencias cinematográficas a través de las equivalencias narrativas y estilísticas, sino también hacer que la mente del lector proyecte su saber filmico sobre aspectos únicamente traducibles en términos cinematográficos como, por ejemplo, la descripción de abajo arriba de los personajes, que a un lector con una mediana cultura filmica le recuerda a una panorámica vertical.

9 Este esquematismo, que hace de la obra literaria algo intencional, le es reconocido también por Ingarden al cine (1979: 358).

10 «The efficacy of a literary text is brought about by the apparent evocation and subsequent negation of the familiar. What at first seemed to be an affirmation of our assumptions leads to our own rejection of them, thus tending to prepare us for a re-orientation» (Iser, 1975: 290). 
Ahora bien, si se acepta que esa instancia de recepción inscrita en el texto que es el «lector implícito» no atiende solamente a las marcas de la enunciación sino que puede actualizar otros aspectos como los temáticos, por ejemplo, y se estima que esa forma cinematográfica puede ser debida en parte a la recepción en España del neorrealismo italiano, con el que coincide en el modo de encarar determinados asuntos, las perspectivas que se abren acerca de un mejor conocimiento de los textos literarios y de su relación con otros que pertenecen a otras nacionalidades, trascienden el análisis narratológico por considerarlo insuficiente desde un planteamiento comparatista de la literatura.

El profesor rumano A. Marino defiende, como ya se ha visto, la necesidad de que la Literatura Comparada sobrepase la mera relación de hechos hacia una poética comparada, autónoma con respecto a otros métodos y basada en una nueva orientación de un concepto tan tradicional de la misma como el de la invariante. En esta línea resulta necesario el tener en cuenta los préstamos del cine a la literatura.

Si pensamos en los textos precedentes comprobamos, por ejemplo, cómo en el fragmento de "Vísperas del silencio» la mirada del pocero arranca del rostro de su compañero ("prematuramente viejo») y después pasa a sus ropas, conectando el trabajo humilde con la vida de quien lo realiza, encadenando por medio de esa mirada atenta al detalle el rostro con las ropas, como si el primero fuese una prolongación de la segunda o viceversa; conexión que se realiza semánticamente a través de la isotopía de lo viejo y gastado, sea el rostro o el jersey tantas veces lavado. Hay una vinculación del hombre con el oficio y también una solidaridad entre quien contempla y lo contemplado. Lo contemplado es algo muy trivial - unas ropas y unos hombres que hacen algo tan banal como salir desde una alcantarilla-, pero la manera de verlo - a la altura del ojo del observadordota a ese acto tan insignificante de un contenido humano de solidaridad.

En el caso de En la hoguera, de nuevo es la ocularización interna de los dos personajes (el gitano e Inés) quien descubre lo que subyace por debajo de los actos de los hombres. La elipsis oculta la violación de Soledad, pero la mirada de Inés descubre no tanto la violencia del acto, cuyas consecuencias son objetivamente perceptibles, cuanto el desastimiento y la indefensión que la desnudez del pie delata; es decir, que la mirada humana del personaje descubre lo que está oculto y la elipsis no ha explicitado: la indefensión ante una naturaleza que se impone a los hombres y mediante el calor los trastorna - y que en la novela del período alcanza uno de sus momentos estelares en El Jarama-, tanto al gitano que la mira con pasión, como a Inés, que reconoce en esa desnudez algo semejante a la suya frente al personaje central de la novela, Miguel, por el que siente una poderosa atracción fisica, aunque igualmente velada. 
Vemos, por consiguiente, algo que caracteriza a la narración literaria española de los años cincuenta y que le viene en parte de la recepción que en España se hace del neorrealismo cinematográfico italiano, con el que coincide: cómo por debajo de lo trivial surge algo más trascendente (la solidaridad) que carga de un sentido nuevo los actos de la banalidad cotidiana ${ }^{11}$, y cómo la forma de mirar de los personajes descubre lo que está oculto y que de repente se revela epifánicamente ante los ojos del lector (una naturaleza agresiva con los hombres) ${ }^{12}$. Ambos casos - solidaridad y relación del hombre con la naturaleza-- nos remiten a uno de los grandes temas del neorrealismo italiano, tanto cinematográfico como literario, el del humanismo (Bazin, 1966: 440-441; Hovald: 74; Leprohon: 110), que en el cine se plasma por medio de esos encuadres tan habituales a la altura del ojo humano, tal como se observa en los ejemplos mencionados. Pero, además, en el segundo caso, nos hallamos igualmente ante un tema común, el del papel de la naturaleza, que tiene una función muy semejante en ambas culturas: la de ligar al hombre con un paisaje que, en el caso de los italianos, derivaba en gran parte de la visión campesina de la historia y de una guerra que había obligado a los partisanos a adaptarse a un terreno físico determinado en su lucha contra alemanes y fascistas - en este sentido es muy significativo el último episodio de Paisà de Rossellini, en el que el encuadre de la cámara reproduce la visión que tienen los partisanos cuando arrastran su cuerpo en medio de los juncos de los pantanos, siendo la naturaleza quien define su mirada (Bazin, 1966: 458-459)-; y en el caso de los españoles habría que relacionar, además de con una visión campesina que se opone a la del franquismo, con esa heterogeneidad del paisaje y de las gentes de España que el régimen de Franco intentaba anular bajo un discurso mitificante y fuertemente homogeneizador. La mirada de Inés en la novela de Fernández Santos al introducir un cierto tipo de alucinación voyeurista (M. Bal, 1989: 133-150) no permite al lector únicamente una posición moral de horror ante el delito o de complacencia erótica, sino que la reorienta hacia un sentido ideológico característico de los neorrealismos italiano y español.

11 Cesare Zavattini, el gran guionista italiano que tanta relevancia tendrá en la España de los años cincuenta, además de afirmar que "Lo banal no existe» (Caro Baroja, 1955: 201) y que «No hay un día, una hora, un instante de un ser humano que no sea digno de ser comunicado a los demás» (Zavattini, 1952: 13), entiende el cine como una epopeya de nuestras naderias (Zavattini, 1953: 12). Algo muy semejante a lo que pensaba Aldecoa al hablar de una novela que tratase la «épica de los grandes oficios» (1955: 37), y su compañero de generación Sánchez Ferlosio: «muchos pequeños motivos y la novela son los pequeños motivos, la vida cotidiana, el lenguaje vulgar, tienen honda significación a veces» (1956: 4).

${ }_{12}$ Guido Aristarco señala ese carácter epifánico del neorrealismo: «la véritable nouveauté du néoréalisme italien est d'avoir trouvé un langage de modernité par rapport à la narration littéraire [...], le cinéma néoréaliste part des fatti ainsi nommés par Zavattini, qui ont l'air insignifiants mais qui ont ce grand pouvoir d'explorer en face de nous, et de former des choses extrêmement importantes» (Questerbert, 1988: 232). 
Por lo tanto, se comprueba cómo para llegar al establecimiento de una invariante tematológica sobre el humanismo o sobre la relación campo/ciudad que se base en las semejanzas a lo largo del tiempo y del espacio de las diversas literaturas, y entre ellas la italiana y española del período de posguerra, no se puede prescindir del neorrealismo cinematográfico italiano, ya que a través de él se reciben en España ambos temas. Si al mismo tiempo, y en un ejercicio de sincronía que haga contemporáneas épocas y culturas pasadas para el que la Literatura Comparada ha de estar dispuesta (Marino, 1988: 171-179), comparamos el tratamiento del tema ciudad/campo a lo largo de la historia, con el objeto de acercarnos a esa invariante, constataremos que, al margen de las posibles semejanzas, las diferencias que se dan en el neorrealismo responden en gran medida a un origen filmico: el carácter epifánico de una mirada que no se le atribuye al narrador sino a los personajes, y por medio de la cual el lector descubre algo trascendente que de pronto se le revela bajo lo oculto.

Es el cine, pues, quien en este caso establece la semejanza o la diferencia, al igual que antes había señalado el franqueo del umbral narratológico hacia espacios más vastos, como el de la tematología o el de la fortuna de un movimiento literario fuera de sus fronteras, espacios tradicionalmente reservados a la Literatura Comparada.

$Y$ de ahí que se pueda concluir señalando dos hechos importantes que se desprenden de todo lo anterior: que el análisis narratológico por sí solo no explica suficientemente los textos desde una perspectiva comparatista de la literatura, aunque es un punto de partida fundamental para cualquier estudio del impacto del cine sobre ésta; y que la investigación de las repercusiones de aquél sobre la literatura nos aboca hacia esa supranacionalidad y ese especifico literario que todos los comparatistas exigen como condición indispensable para que pueda hablarse de Literatura Comparada.

\section{Referencias Bibliográficas}

AldecoA, I. (1955). Destino 956, 3 diciembre, 37.

- $\left(1981^{5}\right)$. Cuentos completos. 2. Madrid: Alianza.

AYALA, F. (1991). «Taracea cinematográfica». El Pais, 18 octubre, 15-16.

BAL, M. (1989). «Visual Readers and Textual Viewers». Versus 52-53, 133-150.

BAZIN, A. (1966). ¿Qué es el cine? Madrid: Rialp.

Calvino, 1. (1983). Punto y aparte. Ensayos sobre literatura y sociedad. Barcelona: Bruguera.

CARo Baroja, P. (1955). El neorrealismo cinematográfico italiano. México: Alameda. 
ClERC, J.-M. (1981). «Les écrivains français devant le cinéma de 1925 à 1965: Aperçu historique sur le notion d'influence du cinéma». En Proceedings of the IXth Congress of the International Comparative Literature Association, 303-307. Innsbruck.

COHEN, K. (1979). Film and Fiction. The Dynamics of Exchange. New Haven/London: Yale University Press.

COMPANY, J. M. (1986). La realidad como sospecha. Valencia: Hiperión.

- (1987). El trazo de la letra en la imagen. Madrid: Cátedra.

Chatman, S. (1980). "What Novels Can Do That Film's Can't (And Vice Versa). Critical Inquiry 7, 121-140.

ECO, U. (1981). Lector in fabula. Barcelona: Lumen.

FERNÁNDEZ SANTOS, J. (1976). En la hoguera. Madrid: EMESA.

GADAMER, H. G. (1989). «Historia de efectos y aplicación». En Estética de la recepción, R. Warning (ed.), 81-88. Madrid: Visor.

Genette, G. (1972). Figures III. Paris: Du Seuil.

GIMFERrer, P. (1985). Cine y literatura. Barcelona: Planeta.

GORDILlo, I. (1988). «Literatura y Cine: Bibliografía en Español». Discurso 2, 95-108.

GuillÉn, C. (1985). Entre lo uno y lo diverso. Barcelona: Crítica.

HAMON, Ph. (1981). Introduction à l'analyse du descriptif. Paris: Hachette.

Hedges, I. (1983). Languages of Revolt: Dada and Surrealist Literature and Film. Durham D.C.: Duke University Press.

Henderson, B. (1983). "Tense, Mood, and Voice in Film (Notes After Genette)». Film Quaterly 36, 4-17.

Hovald, P. G. (1962). El neorrealismo y sus creadores. Madrid: Rialp.

INGARDEN, I. (1979²). A obra de arte literária. Lisboa: Fundaçao Calouste Gulbenkian.

ISER, W. $\left(1975^{2}\right)$. The Implied Reader. Patterns of Communication in Prose Fiction from Bunyam to Beckett. Baltimore/London: The Johns Hopkins University Press.

- (1987). El acto de leer. Madrid: Taurus.

JAUSS, H. R. (1976). La literatura como provocación. Barcelona: Península.

- (1978). Pour une esthétique de la réception. Paris: Gallimard.

JOST, F. (1983). «Narration(s): en deça et au-delà». Communications 38, 192-212.

- $\left(1989^{2}\right)$. L'oeil-caméra. Entre film et roman. Lyon: Presses Universitaires.

KIBÉDI VARGA, A. (1981). «Réception et classement: lettres-arts-genres». En Théorie de la Littérature, A. Kibédi Varga (ed.), 210-227. Paris: Picard.

LEPROHON, P. (1978). Le cinéma italien. Paris: D'Aujourd'hui.

Machado, A. M. y PageauX, D. H. (1988). Da Literatura Comparada à Teoria da Literatura. Lisboa: Ediçoes 70.

Marino, A. (1988). Comparatisme et théorie de la littérature. Paris: PUF.

MITRY, J. (19894). Estética y psicologia del cine. 2. Las formas. Madrid: Siglo XXI.

MORRIS, C. B. (1972). Surrealism and Spain 1920-1936. Cambridge: University Press.

- (1980). This Loving Darkness. The Cinema and Spanish Writers 1920-1936. New York: Oxford University Press.

MorrisseTtE, B. (1985). Novel and Film. Essays in Two Genres. Chicago/London: The University of Chicago Press.

PAECH, J. (1988). «Literatur und Film». Film Theory 19-20, Münster Maks.

PeñA-Ardid, C. (1992). Literatura y cine. Madrid: Cátedra. 
PiChoIS, C. y RousSeAU, A.-M. (1969). La literatura comparada. Madrid: Gredos.

QUESTERBERT, M.-C. (1988). Les scénaristes italiens. 5 Continents.

RiCARdou, J. (1967). Problèmes du nouveau roman. Paris: Du Seuil.

RobBe-Grillet, A. (1973). Por una novela nueva. Barcelona: Seix Barral.

Ropars-Wuilleumier, M. C. (1990). Écraniques. Le film du texte. Presses Universitaires de Lille.

Ross, H. (1987). Film as Literature. Literature as Film. New York: Greenwood Press.

SÁNCHEZ FERLOSIO, R. (1956). La estafeta literaria 41, 29 abril, 4.

SCHMELING, M. (1984). «Introducción: Literatura General y Comparada. Aspectos de una metodología comparatista». En Teoria y praxis de la literatura comparada, M. Schmeling (ed.), 5-38. Barcelona/Caracas: Alfa.

SCHMITT-VON MÜHLENFELS, F. (1984). «La literatura y las otras artes». En M. Schmeling, (ed.), 169-193.

SCHOLES, R. (1982). Semiotics and Interpretation. New Haven/London: Yale University Press.

TENORIO, I. (1989). «Cine y Literatura: Bibliografía en francés». Discurso 3-4, 89-104.

- (1991). «Cine y Literatura: bibliografía en italiano». Discurso 7, 89-101.

URRUTIA, J. (1983). Imago litterae, cine, literatura. Sevilla: Alfar.

- (1992). Literatura y comunicación. Madrid: Instituto de España/Espasa-Calpe.

UTRERA, R. (1981). Modernismo y 98 frente a cinematógrafo. Universidad de Sevilla. VANOYE, F. (1989). Récit écrit. Récit filmique. Paris: Nathan.

Varios Autores (1991). Surrealistas, surrealismo y cinema. Barcelona: Fundación «La Caixa».

Vernet, M. (1988). Figures de l'absence. Paris: Éditions de l'Etoile.

VirmauX, A. y O. (1976). Les surréalistes et le cinéma. Paris: Seghers.

WEISSTEIN, A. (1975). Introducción a la literatura comparada. Barcelona: Planeta.

WelleK, R. (1968). Conceptos de critica literaria. Universidad Central de Venezuela.

WELleK, R. y WARREN, A. $\left(1969^{4}\right)$. Teoria literaria. Madrid: Gredos.

ZAVATTINI, C. (1952). Indice 49, 15 marzo, 13.

- (1953). "Cesare Zavattini, la literatura en el cine y la historia de Ladrón de bicicletas). Correo literario IV, 68, 15 marzo, 12. 